\title{
On the external and internal resonance phenomena of the elastic bodies with the complex oscillations
}

\author{
Huzyk N. ${ }^{1}$, Pukach P. ${ }^{2}$, Sokil B. ${ }^{1}$, Sokil M. ${ }^{2}$, Vovk M. ${ }^{2}$ \\ ${ }^{1}$ Hetman Petro Sahaidachnyi National Army Academy, \\ 32 Heroes of Maidan Str., 79026, Lviv, Ukraine \\ ${ }^{2}$ Lviv Polytechnic National University, \\ 12 S. Bandera Str., 79013, Lviv, Ukraine
}

(Received 3 March 2021; Revised 30 December 2021; Accepted 3 January 2022)

\begin{abstract}
Complex nonlinear oscillations in the elastic bodies are studied using a priori information about the oscillations form and taking into account a refined mathematical model of the second (other) form of oscillations. Application of existing methods or development of the new ones for the analysis of received non-autonomous boundary value problems is proposed. The effectiveness of the practical implementation of the discussed methodology significantly increases in cases where the magnitude of the elastic body displacements due to the one form of oscillations is much higher than the other one. To analyze the problem one can use the well-known tested analytical methods for the systems with the small nonlinearity. Torsional and bending oscillations of the elastic body are shown as the example. It is also demonstrated that especially dangerous resonant processes can be caused not only by the external perturbations but also by the internal influence between some forms of oscillations. The obtained results allow to choose the basic technological and operational parameters of the machine oscillating elements in order to avoid the resonance phenomena.
\end{abstract}

Keywords: nonlinear elastic body, asymptotic methods, amplitude, resonance, complex oscillations.

2010 MSC: 34C17, 35L70

DOI: $10.23939 / \mathrm{mmc} 2022.01 .152$

\section{The statement of the problem}

Operation of various types of machines and mechanisms, elastic elements of structures is accompanied, usually, by the oscillations of their elements. Interacting between themselves, they can lead not only to significant dynamic loads, but can also cause failure of the whole object. On the other hand, mathematically, these processes are usually described by ordinary nonlinear differential equations or boundary value problems for the system of partial differential equations. It is possible to integrate the latter except by numerical methods. However, numerical simulation of these equations cannot answer many important practical questions. First, these are the conditions for the existence of internal and external resonances, features of their passage, stability of the process, etc. Therefore, the problem of analytical study of complex oscillations, even for the one-dimensional models of elastic bodies, remains open. In our view, even a approaching analytical study of such complex processes in elastic bodies can give much more information about their dynamics than numerical integration. Therefore, the article develops the main ideas of the methodology which was developed in [1] for the study of complex oscillations in the case of a combination of torsional and bending oscillations. The methodology is based on the idea of using a priori information about one form of oscillation and using it in the construction of a mathematical model of another with the subsequent use or development of analytical methods for the study of the obtained "refined" non-autonomous mathematical model. The methodology is particularly effective for practical implementation when the displacements of elastic body points caused by one form of oscillation are much smaller than the others. In this case, effective analytical methods for the study of relevant mathematical models of elastic body dynamics have been developed for quasilinear or nonlinear elastic body characteristics [2]. 


\section{Material and methods}

The most effective analytical methods for the study of nonlinear oscillations of distributed parameter systems are methods based on the idea of perturbation methods [3]. On the basis of them, in conjunction with the principle of oscillation frequency in nonlinear mechanical systems, the theory of asymptotic integration of quasilinear [2] and nonlinear [4-8] mathematical models of systems with distributed parameters has been developed, provided that the dynamic process in the respective systems can be interpreted as simple (mono) oscillations (longitudinal, transverse, torsional, bending). Further, the indicated methods have been developed for some classes of dynamic systems, characterized by the speed of longitudinal movement, (rope lifts, belt and chain transmissions, belt extended mechanisms, conveyor lines). However, mono oscillations are more the exception than the regularity of dynamic processes, even in elastic bodies. Thus, columns for drilling oil and gas wells perform complex oscillations (a combination of torsional, bending, and in some cases also longitudinal) [9], turbine rotors a combination of torsional and bending $[10,11]$ etc. Separate studies show that these kinds of oscillations in elastic bodies interacting with one another can lead to such undesirable phenomena as internal resonance. Therefore, the development of a methodology of studying of complex oscillations of elastic bodies is an important applied problem. In order to partially solve it, it is proposed to:

a) with the aid of processing of empirical information for the one of the oscillations form describe them by approximate analytic relations (the laws of their changes);

b) take the above laws into account in the mathematical model of other oscillations, which makes it possible to reduce the number of differential equations that together with the boundary conditions describe the dynamics of the object;

c) by the most accessible analytical methods to investigate non-autonomous mathematical models that correspond to unknown oscillations.

A mathematical model of nonlinear torsional oscillations of a rectilinear one-dimensional body that rotates about a fixed vertical axis $O Z$ at an angular velocity $\Omega$ can serve (under certain boundary conditions) a differential equation

$$
\theta_{t t}-\frac{G}{\rho} \theta_{z z}=\frac{1}{I} Q\left(x, t, \theta, \theta_{t}, \theta_{x}, \varphi\right) .
$$

In (1) by $\theta(x, t)$ we denote the angle of rotation of the elastic body, by $I=\rho J_{p}$ - its running moment of inertia relative to the axis of rotation, by $G$ - the shear modulus (modulus of elasticity of the second kind), by $\rho$ - the density of the material of the body. $J_{p}$ denotes the equatorial moment of the cross-section (the moment of inertia of the cross-section), $Q\left(x, t, \theta, \theta_{t}, \theta_{x}, \phi\right)$ is nonlinear with respect to the set of variables, periodic for $\phi=\mu t+\phi_{0}$ function that describes the distribution of the moments of external forces relative to the axis of rotation along the length of the body (including moments of resistance), and $\mu$ denotes the frequency of periodic perturbation.

If, in addition, the body makes the bending oscillations of small amplitudes in the moving plane $X O Z$, then for each element of the length $d z$ there exist the inertia forces of relative motion and Coriolis inertia force [12]. To determine them, we assume that:

a) the running body mass is equal to $m$;

b) the deflection of an arbitrary element with the applique $z$ in the above plane is determined by the function $u(z, t)$;

c) there is no deplanation of flat normal section.

In this case, the inertia force of the relative motion $d \boldsymbol{\Phi}_{r}$ of the specified element (caused by bending oscillations) is determined by the dependence $d \boldsymbol{\Phi}_{r}=-m u_{t t}(z, t) \boldsymbol{i} d z$. Similarly it is determined the Coriolis inertia force $d \boldsymbol{\Phi}_{c o r}$ of the specified element: $d \boldsymbol{\Phi}_{c o r}=-2 m \Omega \boldsymbol{k} \times u_{t}(z, t) \boldsymbol{i} d z=$ $-2 m \Omega u_{t}(z, t) \boldsymbol{j} d z$.

From the above, it follows that the inertia force of relative motion does not affect the torsional oscillations of the body, because their moment relative to the axis of rotation is equal to zero. As for the Coriolis inertia force of the specified element, its moment relative to the axis of rotation is equal to $d M_{z}^{c o r}=d \Phi_{c o r} u(z, t)=2 m \Omega u_{t}(z, t) u(z, t) d z$. 
Thus, the "refined" differential equation of the torsional oscillations of the body, taking into account its small transverse oscillations, has the form

$$
\theta_{t t}-\frac{G}{\rho} \theta_{z z}=\varepsilon\left\{Q\left(x, t, \theta, \theta_{t}, \theta_{x}, \varphi\right)+2 m \Omega u_{t}(z, t) u(z, t)\right\}, \quad \varepsilon=\frac{1}{I} .
$$

Our aim is to obtain basic relations that describe the main parameters of the torsional oscillations of the investigated elastic body under condition that the bending oscillations are described by a known analytical function or a discrete set of amplitude values and oscillation periods. In [12] it is shown that for the simplest forms of oscillations a discrete set of values of amplitudes and periods of bending oscillations of an elastic body can also lead to an analytical dependence. Thus in the below the bending oscillations will be described by dependence

$$
u_{s}(z, t)=\vartheta\left(z, \Xi_{s} t+\vartheta_{0 s}\right)=b_{s} \sin \frac{s \pi x}{l} \cos \left(\Xi_{s}(\Omega) t+\vartheta_{0 s}\right),
$$

where $\Xi_{s}(\Omega) t+\vartheta_{0 s}, \Xi_{s}(\Omega), \vartheta_{0 s}$ denote the phase of bending oscillations, their frequency and the initial phase respectively.

Solving procedure. It is known [2], that not only the acting forces determine the dynamic process of mechanical systems with distributed parameters, but also by the initial and boundary conditions. So we will investigate the basic differential equation (2) under boundary conditions that are consistent with the rotation of the elastic body in ideal bearings, that is

$$
\left.\theta(x, t)\right|_{x=0}=\left.\theta(x, t)\right|_{x=l}=0 .
$$

The restrictions imposed on the right-hand side of the differential equation (1) and the amplitude of the bending oscillations allow to use the main relations of Krylov-Bogolyubov-Mitropolsky method and the principle of the frequency of oscillations for "weakly nonlinear" systems of hyperbolic type [7] for construction of the solution of the boundary value problem (2), (3). According to them, the first approximation of the one frequency asymptotic solution of boundary value problem (2), (3) can be represented in the form

$$
\theta(z, t)=a \sin \frac{k \pi z}{l} \sin \psi_{k}+\varepsilon U\left(a, z, \psi_{k}, \gamma, \phi_{s}\right), \quad \phi_{s}=\Xi_{s}(\Omega) t+\vartheta_{0 s}, \quad \psi_{k}=\omega_{k} t+\psi_{0 k} .
$$

In the formula (4) $\omega_{k}=\frac{k \pi}{l} \sqrt{\frac{G}{\rho}}$ and $U\left(a, z, \psi_{k}, \gamma, \phi_{s}\right)$ is the $2 \pi$ periodic with respect to phase $\psi_{k}, \gamma, \phi$ function that does not contain the oscillation mode $k$. It means that it satisfies the conditions

$$
\int_{0}^{2 \pi} U\left(a, z, \psi_{k}, \gamma, \phi\right)\left\{\begin{array}{c}
\sin \psi_{k} \\
\cos \psi_{k}
\end{array}\right\} d \psi_{k}=0
$$

As for the parameters $a$ and $\psi_{k}$, than for the perturbed motion, they, as a function of time, are determined not only by the right-hand side of differential equation (2), but also by the relations between frequencies $\omega_{k}, \mu ; \Xi_{s}(\Omega), \omega_{k}$ that is, by the frequency of its own torsional oscillation $\omega_{k}$ and the forced $\mu$ or by the frequency of the bending oscillations $\Xi_{s}(\Omega)$. If between these parameters there is a rational relation of the form $p \frac{k \pi}{l} \sqrt{\frac{G}{\rho}} \approx q \mu$ or $p \frac{k \pi}{l} \sqrt{\frac{G}{\rho}} \approx q \Xi_{s}(\Omega)$ ( $p, q$ are relatively simple numbers), then such cases will be called resonant, with the first caused by external periodic perturbation and the second by bending oscillations ("internal" resonance).

Let us dwell in more detail on the resonant oscillations caused by the bending oscillations of the elastic body. The spectrum of the own frequency of bending oscillations of an elastic body rotating about a fixed axis with an angular velocity $\Omega$ under the condition of a quasi-linear oscillation model (this is the model of the system considered), as shown in [2], is determined by the relation conditions $\Xi_{s}(\Omega)=\sqrt{\left(\frac{s \pi}{l}\right)^{4} \frac{E l}{m}-\Omega^{2}}$. Such an internal resonance in the elastic body will exist if the condition

$$
q \sqrt{\left(\frac{s \pi}{l}\right)^{4} \frac{E l}{m}-\Omega^{2}}=p \frac{k \pi}{l} \sqrt{\frac{G}{\rho}}
$$

hold. 
The relation (6) determines the angular velocity of rotation of the body at which resonant oscillations occur at frequencies close to the frequency spectrum of the bending oscillations. We will call this value the resonant angular velocity of rotation. Therefore, the value of the resonant angular velocity is determined by the relation

$$
\Omega_{s k}=\frac{p}{q} \sqrt{\left(\frac{s \pi}{l}\right)^{4} \frac{E l}{m}-\left(\frac{k \pi}{l}\right)^{2} \frac{G}{\rho}} .
$$

We proceed to the definition of the law of change of the basic parameters of torsional oscillations of an elastic body in the form close to one of the forms of "dynamic equilibrium" in the nonresonant case that is under conditions

$$
\Omega_{s k} \neq \frac{p}{q} \sqrt{\left(\frac{s \pi}{l}\right)^{4} \frac{E l}{m}-\left(\frac{k \pi}{l}\right)^{2} \frac{G}{\rho}} \text { and } p \frac{k \pi}{l} \sqrt{\frac{G}{\rho}} \neq q \mu .
$$

In this case, to find the relations that determine the laws of change of the defining parameters of torsional oscillations for the first approximation of the asymptotic solution, we obtain

$$
\begin{array}{r}
\frac{\partial^{2} U}{\partial \psi_{k}^{2}} \omega_{k}^{2}+\frac{\partial^{2} U}{\partial \gamma^{2}} \mu^{2}+\frac{\partial^{2} U}{\partial \phi_{s}^{2}} \Xi_{s}^{2}(\Omega)+2 \frac{\partial^{2} U}{\partial \psi_{k} \partial \gamma} \omega_{k} \mu+2 \frac{\partial^{2} U}{\partial \psi_{k} \partial \phi_{s}} \omega_{k} \Xi_{s}(\Omega)+\frac{\partial^{2} U}{\partial \gamma \partial \phi_{s}} \mu \Xi_{s}(\Omega)-\frac{G}{\rho} \frac{\partial^{2} U}{\partial x^{2}} \\
=F\left(a, x, \psi_{k}, \gamma\right)-m \Omega \Xi_{s}(\Omega) b_{s}^{2} \sin 2 \phi_{s} \sin ^{2} \frac{s \pi}{l} x \\
-2 \frac{d a}{d t} \omega_{k} \cos \psi_{s} \sin \frac{k \pi}{l} x-2 a\left(\frac{d \psi_{s}}{d t}-\omega_{s}\right) \sin \psi_{s} \sin \frac{k \pi}{l} x
\end{array}
$$

In the formula (8) $F\left(a, x, \psi_{k}, \gamma\right)$ is a known function that corresponds to the value of the right-hand side of equation (1), provided that $\theta(x, t)$ and its derivatives take the main values, which are consistent with (4). The conditions imposed on the function $U\left(a, x, \psi_{k}, \gamma, \phi\right)$ allow obtaining basic relations for determining $\frac{d a}{d t}$ and $\frac{d \psi_{k}}{d t}$ :

$$
\begin{aligned}
\frac{d a}{d t} & =-\frac{\varepsilon}{4 \omega_{k} l \pi^{2}} \int_{0}^{l} \int_{0}^{2 \pi} \int_{0}^{2 \pi} F\left(a, x, \psi_{k}, \gamma\right) \sin \frac{k \pi x}{l} \cos \psi_{k} d \gamma d \psi_{k} d x \\
\frac{d \psi_{k}}{d t} & =\omega_{k}-\frac{\varepsilon}{4 \omega_{k} a l \pi^{2}} \int_{0}^{l} \int_{0}^{2 \pi} \int_{0}^{2 \pi} F\left(a, x, \psi_{k}, \gamma\right) \sin \frac{k \pi x}{l} \sin \psi_{k} d \gamma d \psi_{k} d x
\end{aligned}
$$

Thus, in the nonresonant case for the first approximation, the determining parameters of torsional oscillations do not depend on bending oscillations. Resonant oscillations are more complex. Consider the main resonance at the frequency of external periodic perturbation. As shown in [3,4], the amplitude of oscillations during the resonance significantly depends on difference between phase of own and forced oscillations, that is $\vartheta_{1}=\psi_{1}-\gamma$. Introducing the indicated parameter into differential equations (8), after averaging with respect to the linear variable and the phase of the coercive force for the case of the main resonance $(\pi / l \sqrt{G / \rho} \approx \mu)$, we obtain

$$
\begin{aligned}
\frac{d a}{d t} & =-\frac{\varepsilon}{2 \omega_{k} l \pi} \int_{0}^{l} \int_{0}^{2 \pi} F\left(a, x, \vartheta_{1}+\gamma, \gamma\right) \sin \frac{k \pi x}{l} \cos \left(\vartheta_{1}+\gamma\right) d \gamma d x \\
\frac{d \vartheta_{1}}{d t} & =\omega_{1}-\mu-\frac{\varepsilon}{2 \omega_{k} a l \pi} \int_{0}^{l} \int_{0}^{2 \pi} F\left(a, x, \vartheta_{1}+\gamma, \gamma\right) \sin \frac{k \pi x}{l} \sin \left(\vartheta_{1}+\gamma\right) d \gamma d x
\end{aligned}
$$

For the resonance caused by bending oscillations (similarly to the case of resonance at the frequency of external periodic perturbation), entering in equation (8) the phase difference $\vartheta_{k s}=\psi_{k}-2 \varphi_{s}$, after simple transformations we obtain 


$$
\begin{aligned}
& \frac{d a}{d t}=-\frac{\varepsilon}{4 \omega_{k} l \pi^{2}}\left\{\int_{0}^{l} \int_{0}^{2 \pi} \int_{0}^{2 \pi} F\left(a, x, \psi_{k}, \gamma\right) \sin \frac{k \pi x}{l} \cos \psi_{k} d \gamma d \psi_{k} d x-m b_{s}^{2} \Omega_{s k} \Xi_{s}\left(\Omega_{s k}\right) \delta_{k}^{s} \sin \vartheta_{k s}\right\}, \\
& \frac{d \vartheta_{k s}}{d t}=\omega_{k}-2 \Xi_{s}\left(\Omega_{s k}\right)-\frac{\varepsilon}{4 \omega_{k} a l \pi^{2}}\left\{\int_{0}^{l} \int_{0}^{2 \pi} \int_{0}^{2 \pi} F\left(a, x, \psi_{k}, \gamma\right) \sin \frac{k \pi}{l} x \sin \psi_{k} d \gamma d \psi_{k} d x\right. \\
& \left.\quad+m b_{s}^{2} \Omega_{s k} \Xi_{s}\left(\Omega_{s k}\right) \delta_{k}^{s} \cos \vartheta_{k s}\right\},
\end{aligned}
$$

where $\delta_{k}^{s}=\int_{0}^{l} \sin \frac{k \pi x}{l} \sin ^{2} \frac{s \pi x}{l} d x$.

As for the first improved approximation of the solution (finding the function $U\left(a, z, \psi_{k}, \gamma, \phi\right)$ ), it can be easily found by decomposing the unknown function and the right-hand side of equation (8) into series, followed by equating the coefficients at the same harmonics.

As an example, consider the complex oscillations of an elastic body taking into account:

a) nonlinear-elastic properties of its material, which are described by a nonlinear technical law [8];

b) the force of resistance, which depends on the velocity;

c) harmonious external periodic perturbation;

d) empirical information regarding the bending oscillations of the shaft, from which it follows that they can be described with a sufficient degree of accuracy by the relation $\vartheta\left(z, \Xi_{1}(\Omega) t+\vartheta_{01}\right)=$ $b_{1} \sin \frac{\pi x}{l} \cos \left(\Xi_{1}(\Omega) t+\vartheta_{01}\right)$. In this case the right-hand side of the differential equation (2) takes the form

$$
\begin{aligned}
Q\left(x, t, \theta, \theta_{t}, \theta_{x}, \varphi\right)-2 m \Omega u_{t}(z, t) u(z, t) & \\
& =\lambda \theta_{z}^{2} \theta_{z z}-\delta \theta_{t}^{2 r+1}+h \sin \varphi+m \Omega \Xi_{s}(\Omega) b_{s}^{2} \sin 2 \phi_{s} \sin ^{2} \frac{s \pi x}{l},
\end{aligned}
$$

where $\lambda, \delta, h$ are the known constants. As for the nonresonance case the differential equations (9) imply that the amplitude frequency characteristics of the damping oscillations is described by the relations

$$
\frac{d a}{d t}=\frac{\varepsilon \Gamma^{2}\left(\frac{2 r+3}{2}\right)}{2 \pi \Gamma^{2}(r+2)}\left(\frac{G}{\rho}\right)^{r} a^{2 r+1}, \quad \frac{d \psi_{1}}{d t}=\frac{\pi}{l} \sqrt{\frac{G}{\rho}}-\frac{3 \lambda \varepsilon a^{2}}{64} \sqrt{\frac{\rho}{G}}\left(\frac{\pi}{l}\right)^{3} .
$$

For the resonance case at a frequency close to the main frequency of own torsional oscillations, the main parameters of the dynamic process are determined by the above form of the right-hand side of the differential equation (2) by the dependencies

$$
\begin{aligned}
& \frac{d a}{d t}=\frac{\varepsilon \Gamma^{2}\left(\frac{2 r+3}{2}\right)}{2 \pi \Gamma^{2}(r+2)}\left(\frac{G}{\rho}\right)^{r} a^{2 r+1}+\frac{h}{2} \sqrt{\frac{\rho}{G}} \cos \vartheta_{1}, \\
& \frac{d \vartheta_{1}}{d t}=\frac{\pi}{l} \sqrt{\frac{G}{\rho}}-\mu+\frac{3 \lambda \varepsilon a^{2}}{64} \sqrt{\frac{\rho}{G}}\left(\frac{\pi}{l}\right)^{3}-\frac{h}{2 a} \sqrt{\frac{\rho}{G}} \sin \vartheta_{1} .
\end{aligned}
$$

Slightly more complex relations describe resonant torsional oscillations caused by bending oscillations of the shaft (internal resonance). Then from the differential equation (11) we obtain

$$
\begin{aligned}
\frac{d a}{d t} & =\frac{\varepsilon \Gamma^{2}\left(\frac{2 r+3}{2}\right)}{2 \pi \Gamma^{2}(r+2)}\left(\frac{G}{\rho}\right)^{r} a^{2 r+1}+\frac{4}{3} m b_{1}^{2} \Omega_{11} \sqrt{\frac{\rho}{G}} \sqrt{\left(\frac{\pi}{l}\right)^{4} \frac{E I}{m}-\Omega_{11}^{2}} \sin \vartheta_{11}, \\
\frac{d \vartheta_{11}}{d t} & =\frac{\pi}{l} \sqrt{\frac{G}{\rho}-2 \sqrt{\left(\frac{\pi}{l}\right)^{4} \frac{E I}{m}-\Omega_{11}^{2}}}+\frac{3 \lambda \varepsilon a^{2}}{64} \sqrt{\frac{\rho}{G}}\left(\frac{\pi}{l}\right)^{3}-\frac{4}{3 a} m b_{1}^{2} \Omega_{11} \sqrt{\frac{\rho}{G}} \sqrt{\left(\frac{\pi}{l}\right)^{4} \frac{E I}{m}-\Omega_{11}^{2}} \cos \vartheta_{11} .
\end{aligned}
$$

Below, at different values of the lengths of the elastic body and the angular velocities of its rotation, the change of the amplitude of resonant torsional oscillations caused by external periodic perturbation (Fig. 1) and bending oscillations (Fig. 2) is presented. 

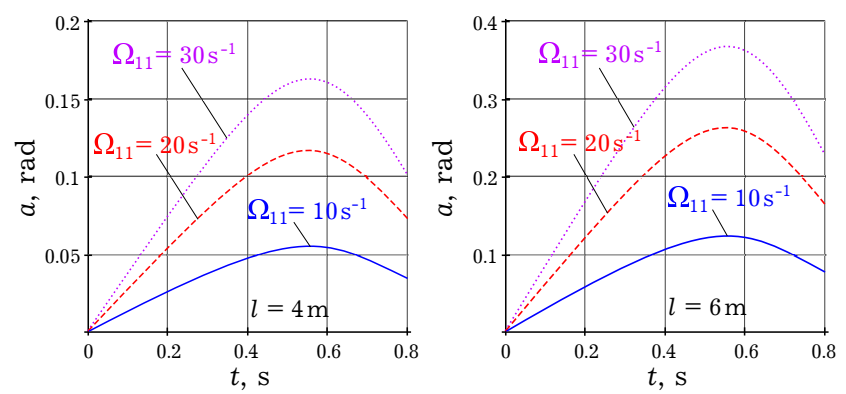

Fig. 1. Changing of the amplitude of torsional oscillations of the shaft during the transition through resonance at the first own frequency at different values of the angular velocity.
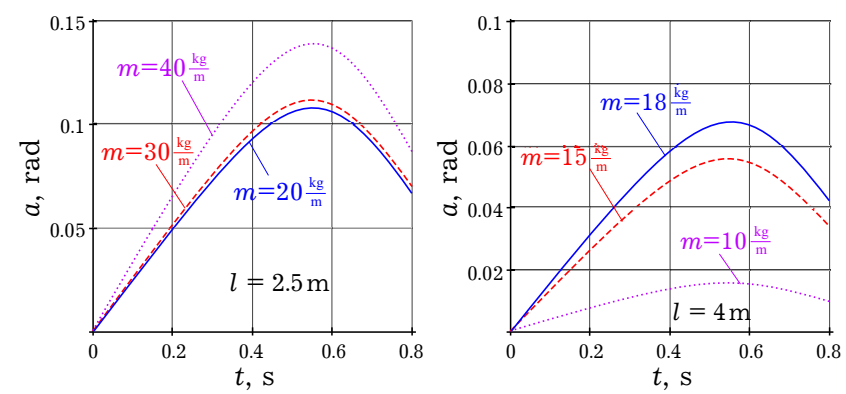

Fig. 2. Changing of the amplitude of torsional oscillations of the shaft during the transition through resonance at the frequency of bending oscillations at different values of the running body mass.

\section{General conclusions}

The basic principles of the methodology of research of complex oscillations of elastic bodies (torsional and bending) are stated in the paper. The analysis of the main results implies:

1) the rotation of an elastic body around the vertical axis affects the frequency of its bending oscillations, namely for the larger values of the angular velocity the frequency of bending oscillations is lower;

2) even small bending oscillations of an elastic body rotating around a vertical axis, at the some relation between the frequencies of torsional and bending oscillations, affect the basic parameters of torsional oscillations;

3) for the case of complex oscillations of the elastic body, resonant oscillations are possible due not only to the external periodic forces (moments), but also to their mutual influence (internal resonances);

4) the amplitude of torsional oscillations in the "fast" transition through resonance at the frequency of external or internal perturbation is less than in the "slow".

The obtained results can serve as a basis to choose the main technological and operational parameters of the machine oscillating elements in order to avoid the resonant phenomena.

[1] Andrukhiv A., Sokil B., Sokil M. Asymptotic method in the investigation of complex nonlinear oscillations of the elastic bodies. Ukrainian Journal of Mechanical Engineering and Materials Science. 4 (2), 58-67 (2018).

[2] Boholyubov N. N., Mitropolsky Yu. A. Asymptotic methods in the theory of nonlinear oscillations. Moscow, Fizmatlit (1974), (in Russian).

[3] Mitropolsky Yu. A., Moseenkov B. I. Asymptotic solutions of partial differential equations. Kyiv, Vyshcha Shkola (1976), (in Russian).

[4] Bayat M., Pakara I., Domairry G. Recent developments of some asymptotic methods and their applications for nonlinear vibration equations in engineering problems: A review. Latin American Journal of Solids and Structures. 9 (2), 1-93 (2012).

[5] Pukach P. Ya. On the unboundedness of a solution of the mixed problem for a nonlinear evolution equation at a finite time. Nonlinear Oscillations. 14 (3), 369-378 (2012).

[6] Cveticanin L. Period of vibration of axially vibrating truly nonlinear rod. Journal of Sound and Vibration. 374, 199-210 (2016).

[7] Cveticanin L., Pogány T. Oscillator with a sum of non-integer order non-linearities. Journal of Applied Mathematics. 2012, Article ID: 649050 (2012).

[8] Mitropolsky Yu. A., Sokil B. I. On the application of Ateb-functions to the construction of an asymptotic solution of the perturbed nonlinear Klein-Gordon equation. Ukrainian Mathematical Journal. 50 (5), 754-760 (1998). 
[9] Sokil B. Construction of asymptotic solutions of certain boundary-value problems for the nonautonomous wave equation. Journal of Mathematical Sciences. 96 (1), 2878-2882 (1999).

[10] Ogorodnikov P., Svitlytskyi V., Hohol V. Study of connection between longitudinal and rotary fluctuations of the drill stem. Oil \& gas industry of Ukraine. 2, 6-9 (2014).

[11] Borshch O., Gulyayev V. Spiral waves in elastic twisted rotating tube rods with internal flows of liquid. Acoustic Bulletin. 10 (3), 12-18 (2007).

[12] Goroshko A., Royzman V. Statistical Methods for Providing the Stability of the Solutions of Inverse Problems and Their Application to Decrease Rotor Vibroactivity. Journal of Machinery Manufacture and Reliability. 44 (3), 232-238 (2015).

[13] Goroshko A. Purpose permissible unbalance for high-speed rotor. Vibrations in engineering and technology. 2 (82), 69-76 (2016).

[14] Pirogova N., Taranenko P. Calculative and Experimental Analysis of Natural and Critical Frequencies and Mode Shapes of High-speed Rotor for Micro Gas Turbine Plant. Procedia Engineering. 129, 997-1004 (2015).

[15] Kyuho Sim, Lee Yong-Bok, Tae Ho Kim. Rotordynamic Performance of Shimmed Gas Foil Bearings for Oil-Free Turbochargers. Journal of Tribology. 134 (3), 031102 (2012).

[16] Do-Kwan Hong, Daesuk Joo, Byung-Chul Woo, Yeon-Ho Jeong, Dae-Hyun Koo, Chan-Woo Ahn, YunHyun Cho. Performance verification of a high speed motor-generator for a microturbine generator. International Journal of Precision Engineering and Manufacturing. 14 (7), 1237-1244 (2013).

[17] Pavlovsky M., Putyata T. Theoretical mechanics. Kyiv, Vyshcha Shkola (1985), (in Ukrainian).

\title{
Про зовнішні та внутрішні резонансні явища у пружних тілах, які здійснюють складні коливання
}

\author{
Гузик Н. ${ }^{1}$, Пукач П. ${ }^{2}$, Сокіл Б. ${ }^{1}$, Сокіл M. ${ }^{2}$, Вовк M. ${ }^{2}$ \\ ${ }^{1}$ Націоналъна академія сухопутних війсък імені гетъмана Петра Сагайдачного, \\ вул. Героїв Майдану, 32, Лъвів, 79012, Україна \\ ${ }^{2}$ Національний університет "Львівсъка політехніка", \\ вул. С. Бандери, 12, 79013, Львів, Україна
}

\begin{abstract}
Складні нелінійні коливання в пружних тілах вивчаються з використанням апріорної інформації про форму коливань та з урахуванням уточненої математичної моделі другої (іншої) форми коливань. Запропоновано застосування існуючих або розроблення нових методів для аналізу отриманих неавтономних граничних задач. Ефективність практичної реалізації методології суттєво зростає у випадках, коли величина переміщень пружного тіла, зумовлена однією із форм коливань, значно перевищує інші. Для аналізу такої задачі можна використати відомі перевірені аналітичні методи дослідження систем із малою нелінійністю. Як приклад розглянуто крутильні та згинальні коливання пружного тіла. Показано, що особливо небезпечні резонансні процеси можуть бути зумовлені не тільки зовнішніми збуреннями, але й внутрішнім впливом між деякими формами коливань. Отримані результати дозволяють вибрати основні технологічні та експлуатаційні параметри елементів машин, які здійснюють складні коливання, щоб уникнути у них явищ резонансу.
\end{abstract}

Ключові слова: нелінійне пружне тіло, асимптотичні методи, амплітуда, резонанс, складні коливання.

Mathematical Modeling and Computing, Vol. 9, No.1, pp. 152-158 (2022) 